\title{
Museums, Challenging Heritage and Social Media During COVID-19
}

\author{
Cassandra Kist
}

The blossoming of museum digital engagement during the pandemic has yielded several promising benefits but also ethical concerns. With the world in a dramatic state of change, it is perhaps more important now than ever that museum professionals engage in discussions about power, (in)justice, (lack of) privilege, comfort and care. According to Kidd (2016), 'challenging heritage', similarly referred to by Macdonald (2009) as 'difficult heritage', can unsettle audiences due to its emotive content. It can dislodge positive identities and prompt uncomfortable questions regarding empathy and responsibility, challenging both museums and audiences. In the context of COVID-19 this raises a pivotal question: can enabling engagement with challenging heritage on social media instigate critical thinking and reflections? And is it ethical to do so?

On the one hand, we may question if it is too soon for visitors who face difficulties during the pandemic to engage in emotional content with potential negative impacts. For example, during a Cuseum webinar, ${ }^{1}$ Emily Haight (Social Media Manager of New-York Historical Society) suggested that due to the pandemic, staff must be 'more sensitive than usual' and as a result, 'sometimes silence is better'. Similarly, during my ongoing research placement with Glasgow Museums, I have observed a tightening of central control on social media due to fears of insensitive messaging. Beyond context, facilitating engagement with challenging heritage on social media raises other ethical concerns due to a reliance on platforms founded upon the commodification of user data, amongst other troubling factors, such as censorship. On the other hand, avoiding social media or focusing on positive content only may eclipse opportunities to support critical thinking in relation to responsibility and empathy.

In fact, many institutions are currently catering to the emotional needs of audiences by creating positive distractions from the pandemic. Compilations of social media and digital initiatives by the UK Museums Association ${ }^{2}$ and the US Museum Computer Network ${ }^{3}$ indicate that these opportunities include collaborative video game sessions, ${ }^{4}$ games such as crossword puzzles, ${ }^{5}$ art prompts, ${ }^{6}$ and learning materials and tools. ${ }^{7}$ These are complemented by humorous projects such as the Twitter take-over by Tim, the security guard at the National Cowboy and Western Heritage Museum (Oklahoma); Sue, the T-rex dancing on our Instagram feeds at the Field Museum (Illinois); and adorable penguins inside the Nelson-Atkins Museum of Art (Missouri). These examples are evidence of museums creating entry points for engagement and innovative connections. Thus, we can infer that some institutions are accommodating audiences that may be lonely, bored, anxious, scared and grieving. But what about the darker things or the 'dark places' (O'Neill 2006)?

A participant at a recent Europeana webinar ${ }^{8}$ highlighted the currently overlooked role of challenging heritage by asking the presenters: 'How can sites dealing with difficult topics (such as Holocaust memorials and former concentration camp sites) create content that suits the visitors' needs in this time of crisis?' We can look to and learn from the social media engagement of institutions such as the Auschwitz Memorial (Poland), the US Holocaust Memorial Museum (US), the Anne Frank House (Netherlands) and the International Slavery Museum (UK). Twitter comments ${ }^{9}$ posted in response to the Auschwitz Memorial offer an entry into the concerns discussed above (figure 1).

One user, echoing many others, responds: 'These true stories are also a spur to do our best in the trying times we find ourselves in now. To act with humanity, to do what we can, to ask difficult questions, to remember the human beings behind the numbers. Mostly,

Museum \& Society, November 2020. 18(3) 345-348 @ 2020, Cassandra Kist. ISSN 1479-8360 


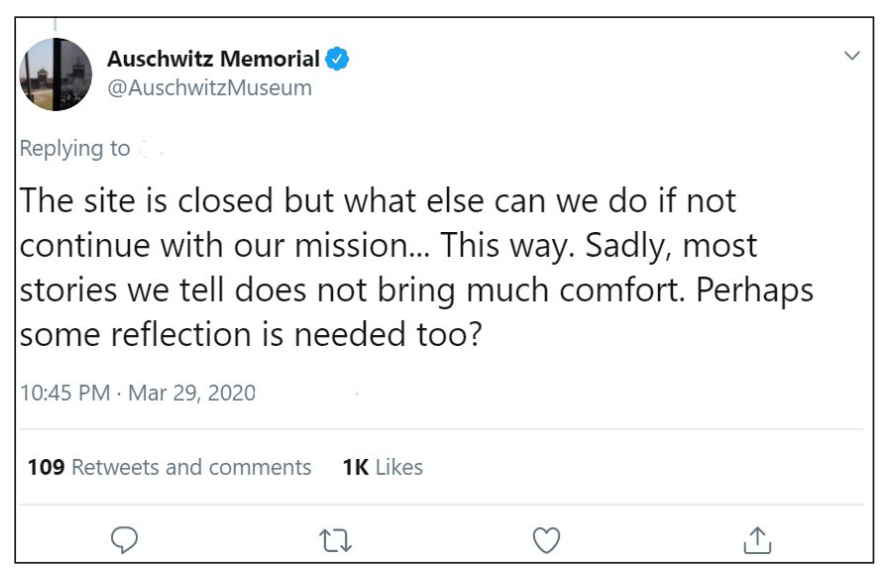

Figure 1: Tweet by @AuschwitzMuseum

however, we must simply \#neverforget'..$^{10}$ Other Twitter comments for the Auschwitz Memorial similarly confirm that the role of challenging heritage continues, especially during a pandemic. It enables users to understand experiences of isolation, make connections to contemporary injustices and, pivotally, to reflect on social responsibility. These qualities also manifest in the recent social media posts and comments of other institutions under discussion.

\section{Reflecting on past and present social responsibility}

The Auschwitz Memorial also enabled reflections on current issues and social responsibility. Recently, a Twitter post criticized a misperception that mandating masks is like forcing Jews to wear stars of David. The comments on this post (approximately 3,000) are too many to cover in depth but often express 'disgust' at this comparison and disbelief at people's unwillingness to wear masks. Users reflect on humanity's selfishness and argue that wearing masks reflects care for others. One user expresses gratitude to the museum for standing up not only to inhumanity in the past but also in the present.

In comparison, upon its closure, the Holocaust Memorial Museum invited Instagrammers to share their previous museum visits and what they learned. This invitation resulted in users recalling personal experiences and lessons regarding the role of ethics and responsibility in the face of injustices. Similarly, recent Instagram video posts by the Anne Frank House which recreate Anne's diary entries also prompt social reflection. Comments left on Anne's video diaries reveal critical thoughts and connections to social issues. For instance, one commenter laments that they are privileged to see a future without isolation or persecution. Additional users criticize their government's inaction during the pandemic, drawing a connection to contemporary issues and responsibility.

\section{Framing contemporary experiences of isolation}

Beyond provoking connections to contemporary issues, the Anne Frank House video diaries also enable understanding of contemporary isolation. These videos encourage a personal connection to Anne's experience of confinement and isolation and deepen understandings of our own. For instance, comments on a recent video diary suggest audiences derive comfort through empathic identification, with some stating that Anne's experiences of being shut in resonate with the world right now. Likewise, the International Slavery Museum encouraged understanding of contemporary COVID-19 experiences by posting a project on Instagram by @migrant_artist_mutual_aid which collected users' experiences of isolation. The museum suggests from all the collected responses that, 'The word 'strength' stands out amongst all... not surprising at all! 6 Our spirits will not be broken!'11 This Instagram post defines isolation as a collective experience and encourages a sense of shared endurance. There appears 
to be a lack of comments on the social media posts in the selected sample that suggest audience dismay or outrage directed at the museums due to perceived insensitivity. Although this would require more systematic research to be confirmed, these examples indicate that difficult or challenging heritage can help audiences understand experiences of isolation and prompt reflections on personal roles and social responsibility.

Currently, we are witnessing a change in museums' investment in digital content, engagement, and infrastructure, raising important questions about the role of social media and the museum. Specifically, we might ask if the increasing use of social media will align with museums' social missions or if social goals will fall to the wayside. The pandemic challenges us as individuals, as collectives and as cultural institutions to provoke change, specifically at a time when people are isolated physically but increasingly connected through social and digital media. The heritage sites above interpreted challenging heritage in a way which enabled reflections on contemporary experiences of isolation and responsibility. This leads to two pivotal questions: will museums leverage both the disruptions of this period and challenging heritage to enable understanding of contemporary events and provoke critical reflections? If museums do, what will the ethical implications of using social media be? These are crucial questions for cultural institutions during and after COVID-19.

Received: 26 June 2020 Finally accepted: 17 August 2020

\section{Notes}

1 Cuseum, 'Webinar: How Museums Can Experiment with Social Media to Boost Audience Engagement During Coronavirus' [Webinar], 2020. https://cuseum.com/webinars/howmuseums-can-experiment-with-social-media-to-boost-audience-engagement-duringcoronavirus-video, accessed 21 June 2020.

2 Rebecca Atkinson, 'How Can Digital Platforms Help Museums Connect to Audiences During Covid-19Emergency?', Museums Association 2020. https://www.museumsassociation.org/ museums-journal/news/19032020-how-digital-platforms-be-used-to-support-musemsduring-covid-19-crisis, accessed 21 June 2020.

3 Lori Byrd-McDevitt, 'The 8 Essential Things Museums are Providing Right Now', Museum Computer Network 2020. https://mcn.edu/8-essential-things/?fbclid=IwAR2zKzpXL3kUz PYZX7Tvv-8DquqpGGFFGMncwn02cuAAico43b9naNax iw, accessed 21 June 2020.

4 Museum of English Rural Life, 25 March 2020. https://twitter.com/TheMERL/ status/1242751265869910016, accessed 1 August 2020.

5 Akron Art Museum, 'Play with Us \#MuseumGames', Medium 2020.https://medium.com/@ AkronArtMuseum/play-with-us-museumgames-dfc5bb5fa2a5, accessed 1 August 2020.

6 Hirshhorn Museum, 11 August 2020. https://www.instagram.com/p/CDtfpngHF1x/, accessed 12 August 2020.

7 Children's Museum Indianapolis, 'Museum at Home', 2020. https://www.childrensmuseum. org/museum-at-home, accessed 1 August 2020.

8 Europeana, 'Europeana Communicators webinar: Culture From Home' [Webinar], 2020. https://pro.europeana.eu/event/europeana-communicators-webinar-culture-from-home, accessed 21 June 2020.

9 The posts and comments selected for discussion in this article provide a glimpse into the complexities of challenging heritage during COVID-19 through diverse dark heritage institutions and are not intended to be representative. Responses to these posts may also change, with comments being continuously added and posts retweeted. 
10 Marion Jones, 29 March 2020. https://twitter.com/AuschwitzMuseum/ status/1244380123270430720, accessed 21 June 2020. (The researcher received user consent to quote and publish their tweet with their username).

11 International Slavery Museum, 4 May 2020. https://www.instagram.com/p/B w6axeHIOS/?utm source=ig web copy link, accessed 1 August 2020

\section{References}

Kidd, J. (2016) 'Introduction to Challenging History in the Museum', in Jenny Kidd, Sam Cairns, Alex Drago and Amy Ryall (eds) Challenging History in the Museum, 1-18, London: Routledge. https://orca.cf.ac.uk/56349/1/Introduction.pdf.

Macdonald, S. (2009) Difficult Heritage: Negotiating the Nazi past in Nuremberg and Beyond, Abingdon: Routledge.

O’Neill, M. (2006) 'Making Histories of Religion', in Gaynor Kavanagh (ed) Making Histories in Museums, 188-99, London: Bloomsbury Publishing.

\section{Author}

Cassandra Kist

URL: https://www.gla.ac.uk/schools/humanities/staff/cassandrakist/

cassandra.kist@glasgow.ac.uk

University of Glasgow

United Kingdom

Cassandra Kist is a $\mathrm{PhD}$ student in the faculty of Information studies at the University of Glasgow and is a Marie Curie Fellow in the Horizon 2020 EU Training Network POEM (Participatory Memory Practices). Her research is investigating how museums do and can use (social) media as an engagement tool in ways that aligns with their social missions. She is particularly interested in the relation between social initiatives and challenging narratives on museums' social media. 